
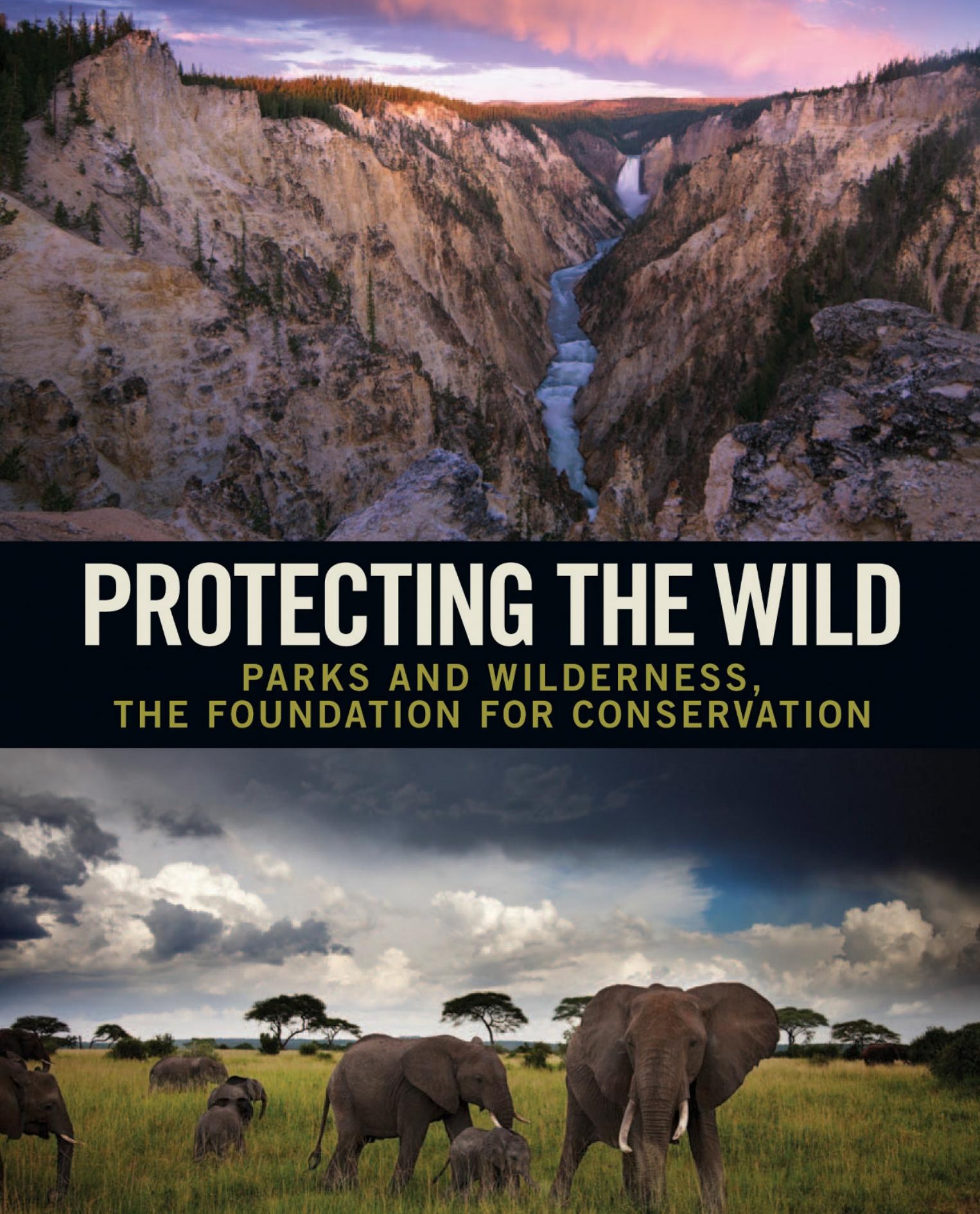

PROTECTING THE WILD 



\section{PROTECTING THE WILD PARKS AND WILDERNESS, THE FOUNDATION FOR CONSERVATION}

Edited by George Wuerthner, Eileen Crist, and Tom Butler 


\section{(c) 2015 by the Foundation for Deep Ecology}

Published by the Foundation for Deep Ecology in collaboration with Island Press.

All rights reserved under International and Pan-American Copyright Conventions.

No part of this book may be reproduced in any form or by any electronic or mechanical means, including information storage and retrieval systems, without written permission from the Foundation for Deep Ecology.

Foundation for Deep Ecology

1606 Union Street, San Francisco, CA 94123

www.deepecology.org

Island Press

2000 M Street, NW, Suite 650, Washington, DC 20036

www. islandpress.org

ISBN 978-1-61091-548-9

Library of Congress Control Number: 2014959302

Grateful acknowledgment is made to the following authors and publishers: Harvey Locke's "Nature Needs (at least) Half" was originally published as "Nature Needs Half: A Necessary and Hopeful New Agenda for Protected Areas," in PARKS: The International Journal of Protected Areas and Conservation (2013) 19.2 and is reprinted here in slightly modified form with permission of IUCN and the author. "Bolder Thinking for Conservation" by Reed Noss et al. is adapted from its original publication in Conservation Biology and is reprinted courtesy of the lead author and used by permission of John Wiley and Sons. "What Is the Future of Conservation?" by Daniel F. Doak et al.was published originally in Trends in Ecology \& Evolution and is adapted here by permission of the lead author and reprinted by permission of Elsevier. George Monbiot's "The British Thermopylae and the Return of the Lynx" appeared originally under a slightly different title in the New Statesman and is reprinted by permission of that magazine and the author. In Spencer R. Phillips's essay, "The Humbling Power of Wilderness," various passages of scripture are taken from THE MESSAGE, copyright @ 1993, 1994, 1995, 1996, 2000, 2001, 2002; used by permission of NavPress Publishing Group. "Another Inconvenient Truth: The Failure of Enforcement Systems to Save Charismatic Species" by Elizabeth L. Bennett was published originally in Oryx and is reprinted by permission of Cambridge University Press and the author.

\section{Book design by Kevin Cross}

Printed in Canada on recycled paper (100\% post-consumer waste) certified by the Forest Stewardship Council 
For Dave Foreman-

Undaunted defender of the wild. 



\section{CONTENTS}

FOREWORD $\quad$ xi

John Terborgh

INTRODUCTION xix

Protected Areas and the Long Arc Toward Justice Tom Butler

PART ONE:

BOLD THINKING ABOUT PROTECTING THE WILD

Nature Needs (at least) Half: A Necessary New

Agenda for Protected Areas Harvey Locke

Bolder Thinking for Conservation Reed F. Noss,

Andrew P. Dobson, Robert Baldwin, Paul Beier,

Cory R. Davis, Dominick A. DellaSala, John Francis,

Harvey Locke, Katarzyna Nowak, Roel Lopez,

Conrad Reining, Stephen C. Trombulak, and Gary Tabor

Caring for People and Valuing Forests in Africa Jane Goodall

What Is the Future of Conservation? Daniel F. Doak,

Victoria J. Bakker, Bruce Evan Goldstein, and Benjamin Hale

Fool's Gold in the Catskill Mountains: Thinking Critically about the Ecosystem Services Paradigm Douglas J. McCauley

Parks, People, and Perspectives: Historicizing Conservation in Latin America Emily Wakild

The Fight for Wilderness Preservation in the Pacific Northwest 
Of Tigers and Humans: The Question of Democratic

Deliberation and Biodiversity Conservation Helen Kopnina

Protected Areas Are Necessary for Conservation

Anthony R. E. Sinclair

PART TWO:

REWILDING EARTH, REWILDING OURSELVES

I Walk in the World to Love It Eileen Crist 82

Rewilding Europe Christof Schenck 96

The British Thermopylae and the Return of the Lynx 105

George Monbiot

Letting It Be on a Continental Scale: Some Thoughts on Rewilding John Davis

Yellowstone to Yukon: Global Conservation Innovations

Through the Years Harvey Locke and Karsten Heuer

Yellowstone as Model for the World George Wuerthner

Rewilding Our Hearts: Making a Personal Commitment

to Animals and Their Homes Marc Bekoff

The Humbling Power of Wilderness Spencer R. Phillips

PART THREE:

PROTECTED AREAS: THE FOUNDATION FOR CONSERVATION

Conservation in the African Anthropocene Tim Caro 164

The Silent Killer: Habitat Loss and the Role of African Protected $\quad 170$ Areas to Conserve Biodiversity Kathleen H. Fitzgerald 
Another Inconvenient Truth: The Failure of Enforcement

Systems to Save Charismatic Species Elizabeth L. Bennett

America Needs More National Parks Michael J. Kellett

194

A New Era of Protected Areas for the Great Plains

208

Curtis H. Freese

Human Impact on Protected Areas of the Peruvian Amazon

Marc J. Dourojeanni

Protected Areas in Chilean Patagonia Carlos Cuevas

Rewilding the Carpathians: A Present-Day Opportunity

Barbara and Christoph Promberger

Protecting the Wild Nature and Biodiversity of the

Altai-Sayan Ecoregion Mikhail Paltsyn

The Crucial Importance of Protected Areas to Conserving

Mongolia's Natural Heritage Richard P. Reading, Ganchimeg

Wingard, Tuvdendorj Selenge, and Sukh Amgalanbaatar

Parks: The Best Option for Wildlife Protection in Australia

Martin Taylor

AFTERWORD

Douglas R. Tompkins

Acknowledgments

Contributors

Notes

Index 



\title{
FOREWORD
}

\author{
JOHN TERBORGH
}

BIOPHILIA-AN INHERENT LOVE of nature and its creatures-is manifested in the fact that nearly all 200 or so nation-states on this planet have formally designated areas for nature protection, the most iconic of them being classified as national parks. In their hearts most people believe this is the right thing to do-that nature and the wild animals, plants, and other organisms it has produced have a right to exist, though the exact meaning of "right" is seldom spelled out. As of today, nations around the world have established more than 130,000 protected areas in the name of conserving nature. Collectively, protected areas encompass roughly 13 percent of Earth's terrestrial realm. (The marine realm, unfortunately, is lagging behind at around 2 percent protected.) This is a significant accomplishment, most of which has accrued during the last fifty years. From the perspective of one who loves nature, this is intrinsically good. It is also tangible evidence that love of nature is a high value shared by virtually all nations and cultures, a value that transcends our differences and rivalries. If this isn't good, what is?

This is the positive side. But recently, a group of contrarian "environmentalists" has promulgated a radically different set of views. A leading claim of this group is that conservation is failing. The claim is based on the undeniable fact that species are still going extinct. Instead of seeing this unfortunate fact as testimony to the relentlessness of human pressures, and to the need to enlarge the scope of nature protection, the contrarians draw a different inference-namely, that continuing extinctions demonstrate that parks and other protected areas are not the answer. But humans have never before presided over an extinction crisis of our own making. 
Even after there was widespread awareness that a global extinction crisis was under way, the fact remained that we did not know how to contain it. The science of biodiversity conservation simply did not exist, leading to many false starts being made in ignorance of the natural processes that maintain diversity. It is fair to say that the science of biodiversity conservation did not mature until around the year 2000. Only a single generation of conservationists has been aware of the science behind landscape-scale networks of protected areas based on a core-buffer-connectivity model and specifically designed to sustain large carnivores and other ecological keystone species and processes. How can one claim with a straight face that conservation is failing and that protected areas are not the answer in light of these realities? The fact that 13 percent of the Earth's land area has been designated for nature conservation speaks to a widespread recognition that protected areas are the answer. Is this a failure? To me it represents an unprecedented global success. How can one account for such a blatant discrepancy in viewpoints?

If the expectation is for immediate and unblemished success, then yes, conservation has fallen short. Species are still going extinct. But is that the point? The question to consider is how many more species would have perished in the absence of protected areas. No one knows the exact answer, but it would surely be a large number compared with the number known to have gone extinct over the last fifty years. The creation of protected areas has slowed but not stopped the global pace of anthropogenic extinction. For all its indispensable work in saving species, neither has the U.S. Endangered Species Act. The (greatly simplified) reason that extinctions continue, despite large areas devoted to nature protection, goes beyond the simple insufficiency of protected habitat to-more importantly-the fact that many existing protected areas are too small, isolated, and lacking in management resources to safeguard them. Much could be gained by consolidating smaller protected areas and restoring habitat continuity between them. Mismatches between the locations of protected areas and those of endangered species amount to another widespread problem in the implementation of conservation worldwide. Despite these shortcomings, there is universal recognition that protected areas are essential not only to preserving nature but to slowing the pace of extinction. Conservation efforts may not have resulted in perfect success, but falling short of perfection does not imply failure. The conservation movement could be given an $\mathrm{A}-$, but certainly not an $\mathrm{F}$. 
If not a conservation strategy based on protected areas intended to sustain native biodiversity, then what? Some of the contrarians who question the value of protected areas propose that the overarching goal of conservation should not be preventing extinctions or preserving biodiversity but instead should be the maintenance of "ecosystem services." Here we run headlong into a collision of values and the ability of words to deceive. Don't get me wrong. I am not against ecosystem services. They are vital, indeed indispensable, to human welfare. Areas managed or conserved with an objective of providing ecosystem services may capture carbon from the atmosphere; protect watersheds from erosion and landslides; provide clean, potable water; restore degraded ecosystems; cleanse contaminants and return oxygen to the atmosphere; and offer aesthetic and recreational benefits. Like nature itself, the ecosystem services that nature provides are good. We could not survive without them.

But please do not confuse ecosystem services with biodiversity conservation, for they are very different things. For example, a plantation of nonnative tree species can provide some ecosystem services almost as well as a native forest, but the biodiversity value of the former is near zero. This is a crucial point that is lost on the contrarians, and unfortunately on much of the public as well. One of the great challenges to be faced by conservationists in the future will be that of clarifying in the public mind the distinction between ecosystem services and biodiversity protection. The two are not necessarily distinct, as when a natural environment provides "services," but they can be completely unconnected, as in the example of the tree plantation, so understanding the distinction requires a level of sophistication that most nonbiologists do not possess. The danger inherent in the contrarians' arguments is that they mislead by appearing to offer a win-win solution, namely that the protection of ecosystem services amounts to nature protection.

As a professor, I always defined conservation science to my classes as the quest to understand how to prevent extinctions. When I began my career fifty years ago, the science of extinction was in a rudimentary state. Populations that were reduced to very small numbers-fewer than 100 individuals-were at risk to the vagaries of fluctuating numbers, skewed sex ratios, and inbreeding. That is about all we could say about extinction and its causality except for a sketchy knowledge that mass extinction events had occurred in the distant past, for example, when the dinosaurs vanished. But at that time we knew almost nothing about mass extinctions as revealed in 
the fossil record. It was not until two decades later that the father-and-son team of Luis and Walter Alvarez discovered that the dinosaurs perished when the Earth was hit by a meteorite 10 kilometers in diameter.

The extinctions occurring today are not attributable to anything so dramatic as a meteorite impact. Instead, species are dying out piecemeal at scattered places around the globe, often with no obvious direct cause that we can discern. That is not to say that there are no consistent patterns. Island species are more vulnerable than their counterparts living on the continents, and freshwater species are more vulnerable than marine species. Jared Diamond summarized the most prominent overarching causes of extinctions, likening them to the four horsemen of the Apocalypse: habitat loss, habitat fragmentation, overexploitation, and alien-species invasions. All of these are clearly important drivers of the contemporary human-driven extinction crisis. So, the critical question is: How can all of these drivers be avoided so that extinctions are prevented? The answer is obvious: Protect and reconnect habitat, exclude poachers, and combat invasion by nonnative species. This is exactly what national parks and other protected areas are intended to do. There is no alternative. Parks and other strictly protected areas are the answer.

But not all parks are equal in protecting against extinction, and herein lies a further complication. The conservation world was thrown into a state of shock in 1985 when William Newmark, then a graduate student at the University of Michigan, published an article stating that some famous national parks in western North America had lost as many as a quarter of their mammal species since the time of their establishment. Newmark's data implied that parks were failing to protect against extinction, but such a facile conclusion would be a dangerous oversimplification. There was a telltale pattern in the data, and it showed that the parks that had suffered the greatest number of extinctions were the smaller ones. The largest protected area in Newmark's sample was the complex of Banff-Jasper-Kootenay-Yoho in the Canadian Rockies. Amounting to a contiguous area of more than 20,000 square kilometers, that complex had experienced no mammal extinctions.

Newmark's results, along with subsequent confirmations, cemented the idea that extinctions could be minimized in large protected areasvery large protected areas. Unfortunately, there are very few protected areas as large as 20,000 square kilometers anywhere in the world (and none in the 48 contiguous United States). So does this mean that we have to accept a continuing trickle of extinctions as inevitable? No-we need large 
protected areas, especially as we now understand, much better than we did in 1985, why small parks fail to maintain their native species.

The science of conservation biology was roughly seven years old in 1985 and still in its infancy. (The birth of a formal science of conservation biology dates to a conference organized in 1978 by Michael Soulé in San Diego.) Since then, we have learned a great deal about the natural forces that stabilize ecosystems and why these forces are disrupted in small areas, be they protected or unprotected.

Among the first species to go extinct in restricted areas are the top carnivores-the wolves, great cats, and bears. Although rare compared to other animals with which they share habitat, such animals have a disproportionate impact on the entire system by regulating the density of prey. Strong regulation maintains the populations of prey species at densities far below those at which they begin to adversely impact the vegetation and each other. In the absence of predation, two broad types of prey become superabundant: herbivores and mesopredators. Although the latter terms may be unfamiliar (especially, that of mesopredator), the phenomena are well known to rural and suburban Americans who nowadays must build fences to protect their gardens from superabundant deer. At the same time, an overabundance of raccoons, opossums, foxes, and feral cats (all mesopredators) is decimating their prey, including songbirds, lizards, frogs, and other small vertebrates and invertebrates.

Here we have two engines of extinction operating simultaneously. Overabundant herbivores are driving changes in the composition of natural plant communities by favoring certain species over others. Trilliums, for example, are a favorite of deer and have decreased precipitously over much of the eastern United States. Meanwhile, an abundance of mesopredators has greatly reduced the number of ground-nesting birds, including such favorites as bobwhite quail, ruffed grouse, and whip-poor-will. Thus, the loss of top predators unleashes a chain of ecological reactions that cascade from one level of the ecosystem to another. Do away with wolves and cougars, and deer overpopulation is an absolutely predictable consequence. The plants at the bottom of the food chain then bear the brunt of the loss of predators. In technical jargon, the chain reaction is called the "trophic cascade." Conservation biologists now understand that the natural state of the trophic cascade with top carnivores present is what stabilizes ecosystems. Interfere with the interaction chain, predator-herbivore-plant or predator-mesopredator-small prey animal, and ecological impoverishment is certain to ensue. 
Now we are able to understand why only the largest protected areas resist extinction. It is because only the largest areas retain their top predators. The statement applies everywhere around the globe. Lion populations in Africa, having disappeared from many smaller parks and game reserves, are an example. The same is true of tigers in India. This forebodes serious management issues in parks that have lost top predators as prey populations increase and begin to compete strongly with one another for dwindling resources. The problem of predator loss also affects a major portion of North America. Wolves once inhabited the entire continent, but they have been relentlessly persecuted and pushed back to the farthest, wildest corners of the land. Cougars, being supremely secretive, have fared better in the West although they have become all but extinct in the East for over a hundred years; hence, the East's deer and mesopredator woes.

All this sounds very discouraging. What gives me hope for a better future is the situation in Europe. Surprisingly, there are wolves in almost every European country except the Benelux nations. And maybe even that qualification is breaking down, as a wolf recently strayed across the border from Germany into the Netherlands. If wolves can coexist with humans in densely crowded Europe, there is no reason other than obstinacy or prejudice that wolves cannot be restored in much larger parts of their native range in North America. If the wolf and cougar were reinstated across the continent, the health of ecosystems could be greatly improved and the threat of extinction would recede. Similar salutary results for the natural world would occur around the world by protecting and reintroducing top predators.

Regarding the U.S. situation, some argue that there is no room in the East, or even in the less populated West, for cougars and wolves, but that argument is a smoke screen promulgated by people who have other reasons for lobbying against the return of predators to American wildlands. Europe proves the argument is wrong. The North American continent can be consolidated and interconnected. Parks along with wilderness areas are the cornerstone of any strategy to restore ecological integrity to North America as well as the rest of the world. However, parks alone cannot restore the normal functioning of ecosystems and prevent extinctions in the areas of the world that are not protected-the vast majority. If there are a few parks where top predators are safe and can breed unmolested, these can serve as population nuclei out of which individual animals can disperse to establish other breeding nuclei in unprotected portions of the land. 
Wolves and cougars don't require pristine conditions to thrive; they require freedom from persecution. They routinely roam through agricultural lands, forests, and prairie, even suburbs. So long as the habitat remains in large pieces and is not crisscrossed by high-speed highways, it can be used by large predators that are far more interested in prey than in the details of habitat quality. The need for predator restoration across North America is abundantly apparent and conditions are suitable, at least in many parts of both the East and West. Globally, the same "rewilding" lessons apply. We need to build the safety nets for large carnivores, expanding and interconnecting protected areas around the world. While the political will is still lagging, enthusiasm for rewilding is everywhere on the rise.

The Earth is currently in the throes of the sixth global extinction crisis, of that there is little doubt. But this sixth crisis differs from the five that preceded it, in that it is self-inflicted. Species are going extinct a thousand times faster than they would in the absence of human impact, and life scientists warn that the biosphere could lose 50 percent of its species by the end of this century if we fail to protect the natural world and chart a new relationship with it. We-and we alone-are responsible, as we are responsible for global climate change and environmental abuses of many kinds. I am old enough to remember the sudden decline of bald eagles in the 1960s, the impact of Rachael Carson's Silent Spring, and the ensuing environmental fervor that lead to the first Earth Day in 1970 and to a subsequent global surge of enthusiasm for "sustainability." Yet it seems to me that we are further from achieving ecological sustainability today than we were several decades ago. As a global society, we are distracted by too many other issueswars, epidemics, unemployment, a struggling economy. In the cacophony of daily events, we appear to have lost sight of the fundamental importance of a healthy biosphere to the well-being of both humans and nature. Restoring confidence in the future can come about only through a renewed commitment to ecological sustainability inspired by a vision of a beautiful, secure, and equitable future. Such a future must be grounded in an enlightened relationship with the Earth in which the needs of nature are recognized as commensurate with those of humanity. For that, the global strategy must be to expand the number and size of protected areas, interconnect them, and rewild them. All other roads lead to an intensification of the sixth extinction crisis and to an impoverished future for humanity. 



\section{INTRODUCTION}

\section{Protected Areas and the Long Arc Toward Justice}

TOM BUTLER

CRAYFISH ARE CRUNCHY. And, it appears, tasty. Sound travels easily over water, and we can hear each distinct bite as an otter devours a crustacean across the pond from where our canoes float. Curious about the passing travelers, the pair of otters has retreated to a mudflat; they gambol about for a while, then sit, partially submerged and attentive. They watch us, unperturbed, while one finishes his snack. We enjoy their company for a time, and paddle on.

Where are we? First and foremost, we are uninvited but seemingly welcome guests in the home of otters. Three canoeing buddies and I are exploring an expansive wetlands complex in New York's Adirondack Park, the largest park in the contiguous United States, a 125-year-old patchwork of private and public land, the latter of which comprises the Adirondack Forest Preserve. The Forest Preserve is protected as "forever wild"; in perpetuity there can be no logging or development on these public lands. In the lexicon of conservation, we are in a "protected area."

On this brilliant late summer day, we have witnessed the aforementioned otters crunching, kingfishers cavorting, a northern goshawk plying the skies, and a gray jay, so typical of this boreal forest country, perched upon a larch at water's edge. Black bears, fishers, coyotes, deer, and moose 
are here, too, unseen today, but undoubtedly preparing for the long winter in this northern realm, not far from the Canadian border. And indeed, the landscape looks like much of eastern Canada, with spruce and fir interspersed with some species more typical of the northern hardwood forest to the south, sugar maple and yellow birch in particular.

Everywhere one looks the sights are pleasing to the eye-water and treeclad hills stretching to the distance. The smells are earthy, piney and sprucey with a dollop of Christmastime (balsam) that will mix with our campfire smoke this evening. The sounds are also noteworthy-the occasional chattering of chickadees and wail of a loon wafting over the water, and between these natural noises a background sound track of ... nothing. No traffic. No chain saws. No motors of any kind. Silence, the rarest of privileges in a world of 7-plus billion humans transforming the world in our image.

These are the gifts of the wilderness for those of us lucky enough to have time and the inclination to seek them out. The effort to reach what I'll call "Otter Pond" was modest-some hours of paddling and portaging, with one quick dunk in cold water when I lost my footing while dragging the canoe upstream over rocky shallows. The return on this muscular investment was extraordinary-the opportunity to experience beauty, spiritual refreshment, and the companionship of old friends, to reminisce with them about previous wilderness adventures and to contemplate future ones. Another gift was solitude. In a park that is within a day's drive of 60 million people, during the height of tourist season, we spent four days in the woods and saw no one else.

Our trip was not epic. No grizzlies charged us. No mist-shrouded summits were conquered. The scenery, while lovely, was commonplace to the region.

What is remarkable is the resurgence of wildness across the landscape. For more than a century, the area we canoed had been subject to intensive exploitation and manipulation at the hands of men (gender exclusivity intended). A moldering wooden dam at the pond outlet and an old railroad bed through the wetlands were some of the infrastructure that supported past logging operations. Not far from our campsite we found the remains of a former settlement along that long-defunct railroad; in the 1910s it had included a depot, sawmill, post office, etc. Now it is barely visible, just some crumbling foundations covered with moss, trees growing skyward where a roof once shed rain. In 1923 a forest fire swept through the area and rewilding commenced. Today the land is more wild than it was a century ago, and because of its conservation, in another century it is likely to 
be wilder still, and therefore more resilient to climate change effects.

Otter Pond is representative of the Adirondacks and so many other places where nineteenth-century timber barons scalped the land and moved on. Reacting to that rapacious logging, conservationists who were concerned about deforestation, associated watershed degradation, and collapse of wildlife populations succeeded in having New York establish a "Forest Preserve" including lands in the Adirondacks and the Catskills in 1885. At a constitutional convention the following decade, the clause ensuring that the public lands comprising the Adirondack and Catskill Forest Preserves would remain "forever wild" was incorporated into New York's state constitution. ${ }^{1}$ (That conservation landmark celebrates its 120 th anniversary this year.)

The pioneering conservationists who were responsible-among them the civil rights lawyer Louis Marshall, who was father of Wilderness Society cofounder Robert Marshall-blazed a path that still leads toward expanding beauty and health. Indeed, the Adirondack Park may be the greatest example of rewilding on Earth, the fullest expression of the incremental reforestation of the northeastern United States following the first wave of logging associated with European colonization of North America. Those otters at home in the Adirondack Forest Preserve, we visitors enjoying a sojourn in the forest, and future generations of wild residents and human recreationists owe earlier conservationists an immense debt of gratitude. Because of conservation action, the Adirondacks are more ecologically vibrant, provide more secure wildlife habitat, and are a more intact canvas for natural processes to create, shape, and sustain biodiversity than other parts of the Northeast $\mathrm{t}^{2}$ outside protected areas. That the Adirondack Park also provides tremendous social and economic values including watershed protection, the initial reason for its creation, is equally clear.

The landscape here is not pristine. It is not virginal, a place where, in the marvelous mixed metaphor attributed to the late David Brower, "the hand of man never set foot." The designated "wilderness" and "wild forest" units that make up the Adirondack Forest Preserve are free, consistent with the etymological roots of the word "wilderness," to follow their own course. They are self-willed lands, home to self-willed creatures.

The Adirondack Park is part of an amazing legacy of protected areas that now cover approximately 13 percent of Earth's land surface. (That percentage includes all categories of conserved land, from strictly protected natural areas to places managed for "sustainable" resource production.) 
Across the planet, every national and state park, wilderness area, wildlife refuge, nature sanctuary, or other permanently conserved habitat exists today for one reason only: because an individual or group of individuals worked to have them protected. There is a grand history here; it is global in scope, and that historical narrative helps inform current discussions and debates about the future role of protected areas.

During the few months bracketing my Adirondack canoe trip, conservationists in the United States noted several landmarks:

The first is that 2014 marked the 150th anniversary of the Yosemite land grant when President Abraham Lincoln signed legislation giving Yosemite Valley to the state of California for its permanent protection with the condition that the land "be held for public use, resort, and recreation." That action put the federal government in the conservation business, setting the stage for the creation of Yellowstone, the world's first national park, the following decade. ${ }^{3}$ (Yosemite Valley would come back into the federal domain several decades later after Yosemite National Park was established.)

A second landmark was the hundred-year anniversary of the death of the last passenger pigeon, ${ }^{4}$ a captive bird named Martha. Formerly the most abundant bird species in North America (and perhaps anywhere on Earth), passenger pigeons entered the dark night of extinction in 1914. Martha died alone in the Cincinnati Zoo, a testament to the shattered myth that nature was inexhaustible and endlessly resilient.

Landmark three was the 50th anniversary of the Wilderness Act of 1964, which created America's national wilderness preservation system. The result of years of grassroots organizing and advocacy, the law is surely one of the most eloquent statutes ever passed, its language largely the work of Howard Zahniser, then executive secretary of the Wilderness Society. ${ }^{5}$ Zahniser's pen was well used, inscribing more than 60 drafts before the final version became law. Not incidentally, Zahniser was a part-time resident of the Adirondacks, his family having a vacation cabin there, where he sometimes worked on those many drafts of the wilderness bill. " "Zahnie," as his friends called him, had been introduced to the region by conservationist Paul Schaefer, a tireless defender of the park's wild rivers during the midcentury era when dam building was all the rage. Schaefer's activism had been influenced, in part, by the Adirondacks' preeminent family of wilderness advocates, the Marshalls. Schaefer first met Robert Marshall atop Mt. Marcy, New York's highest peak, in 1932, and was a longtime conservation colleague of his brother, George Marshall, following Bob's untimely death. ${ }^{7}$ 
These three anniversaries reveal something about the evolution of arguments for protected areas. It's interesting to me that as the arguments for conserving protected areas morphed from aesthetic and recreational to scientific and ecological values- "from scenery to nature" in Dave Foreman's concise summation ${ }^{8}$ - previous rationales were not abandoned, but built upon. To apply a geological metaphor, there has been deposition and accretion, but not erosion.

The suite of reasons undergirding advocacy for parks and wilderness areas deepened with the insights emerging from the fields of landscape ecology and conservation biology in the latter decades of the twentieth century. This did not, however, make moot the earlier, experiential arguments for conservation. Millions of us who visit national parks each year still are motivated by the scenic beauty of wild nature. We who seek to enjoy the freedom of the wilderness with family and friends still treasure the experience of muscle-powered recreation in a primitive setting and the challenge of developing appropriate skills for travel in wild country. Some 168 years after Henry David Thoreau was buffeted by howling winds atop Mount Katahdin-later describing the "Titanic" scenery he encountered there and averring that the "mossy and moosey" Maine woods were "no man's garden"-we feel exactly the same awe at natural forces in a wilderness setting. But there are now far fewer places on Earth one could describe as intact, primeval, wild, or ungardened, far fewer places where wildlife is secure from the pressures, direct and indirect, of a burgeoning humanity.

Which is why, of course, flocks of passenger pigeons no longer darken the skies and vast herds of bison no longer rumble across the Great Plains of North America. And why modern conservationists have viewed protected areas and wildlife protection laws as the key tools for combating the human-caused extinctions of our fellow members in the community of life. The conservation movement in the United States arose as a counterpoint to the loss of wilderness and wildlife as Euro-American culture swept across the continent. Conservation ideas, and particularly the national park concept, spread quickly across the globe and were widely embraced in diverse cultures.

When American conservationists succeeded in passing the Wilderness Act in 1964, the law didn't just codify the notion that some places should remain off-limits to resource exploitation; it also reflected a century's worth of intellectual development in conservation philosophy and practice. Implicitly, the law acknowledged that wild places have intrinsic 
value, regardless of their utility to people. In a notable bit of historical congruence, Congress also enacted a major piece of civil rights legislation in 1964. ${ }^{9}$ It extended rights to a marginalized category of people whose skin had more melanin than that of the country's ethnic majority. That law did not magically abrogate racial prejudice but helped expand justice.

The Wilderness Act did the same, moving society toward a more equitable relationship between people and nonhuman nature. In effect, the law suggested that humanity's sphere of ethical concern should expand to embrace all members of the biotic community, including traditionally marginalized members such as large carnivores. This is a remarkable idea to emerge in an extraction- and use-focused culture, which has viewed the landscape almost exclusively through the lens of economic possibility: "How can I profit from this place? Can I log it, or mine it, or graze it? How can I make it my garden?"

A century and a half of conservation experience tells us that protected areas are popular, effective, ${ }^{10}$ and broadly supported-but almost always controversial before establishment and sometimes long after. Land conservation stimulates strong feelings, particularly on the wilderness end of the spectrum but even sometimes when sustainable resource production is the objective. Land use is deeply personal. It is no surprise when communities with economic and cultural ties to particular extractive industries-industrial forestry and paper production in Maine, for example, or ranching and wool production in Patagonia-are skeptical about proposed protected areas. While there are exceptions to this norm, parks and wilderness areas very often have been the targets of such hostility from "traditional" resource users.

What is perhaps more surprising is when protected areas are attacked from the left for being the colonialist residue of Western imperialism. In truth, the modern conservation movement arose as a counterrevolutionary force in response to the land degradation and wildlife holocaust associated with the expansion of industrial civilization, a wave that extirpated indigenous cultures as well as native species. The movement's foremost tool-protected areas-rejects a colonialist, imperialist attitude toward the living Earth. The designation of protected areas is an expression of humility about the limits of human knowledge and a gesture of respect toward our fellow creatures, allowing them to flourish in their homes without fear of persecution. 
PERHAPS NOT SURPRISING but discouraging is when it becomes trendy to attack parks and wilderness using strawman arguments. This seems to occur periodically and, unfortunately, the latest rhetorical dustup is under way. Indeed, it is the reason for this book, and for its companion volume, Keeping the Wild: Against the Domestication of Earth, ${ }^{11}$ which constructively critiques a nexus of ideas being advanced by so-called new environmentalists or social conservationists. These ideas include:

- The Anthropocene has arrived, and humans are now de facto planetary managers;

- If "pristine wilderness" ever existed, it is all gone now; moreover, focusing on wilderness preservation has poorly served the environmental movement;

- Nature is highly resilient, not fragile;

- To succeed, conservation must serve human aspirations, primarily regarding economic growth and development;

- Maintaining "ecosystem services," not preventing human-caused extinction, should be conservation's primary goal;

- Conservationists should not critique capitalism but rather should partner with corporations to achieve better results;

- Conservation should focus on better management of the domesticated, "working landscape" rather than efforts to establish new, strictly protected natural areas.

This last point regarding the future role of protected areas is of such crucial importance that we have developed Protecting the Wild to consider it. Should the primary goal of conservation be to establish systems of interconnected conservation reserves across the globe-anchored by strictly protected areas such as national parks and wilderness areas-intended to halt the extinction crisis and sustain the evolutionary flourishing of all Earth's biota?

Or is such a goal of planetary rewilding a naive dream in a time of ballooning human numbers, with the demographic trajectory headed toward 10 billion or more people, the majority of whom will live in poverty? Given this context, should conservation give up on its core commitment of stopping anthropogenic extinctions and instead focus on humanized, managed landscapes intended to produce "ecological services" for people?

These questions are addressed in Protecting the Wild by a prominent 
cast of scientists, academics, and conservation practitioners from multiple continents. After a foreword by tropical ecologist John Terborgh, the book is organized into three sections-"Bold Thinking About Protecting the Wild"; "Rewilding Earth, Rewilding Ourselves"; and "Protected Areas, the Foundation for Conservation." The volume concludes with an afterword by Douglas Tompkins, the businessman-turned-conservation philanthropist. With his wife Kristine McDivitt Tompkins-former CEO of Patagonia Inc.-and colleagues, Tompkins has helped conserve well over 2 million acres, creating or expanding five national parks in Chile and Argentina.

The latest of these, the 130,000-hectare El Impenetrable National Park in the Chaco Province of northern Argentina, was formally established as Argentina's 32nd national park with a unanimous vote in Congress just before this volume went to press. As with most contemporary, large-scale conservation initiatives, it was a public-private collaboration. Argentine conservationists worked tenaciously to develop political support and raise funds to support the project. ${ }^{12}$ The positive outcome for wildlife and local communities was made possible by broad-based fundraising and a major gift from a family foundation established by Tompkins.

This is not an isolated victory. Using science, passion, and ethical persuasion, conservationists are striving and succeeding to expand protected areas around the globe. In November of 2014, thousands of advocates from some 160 countries gathered at the World Parks Congress to chart the future direction of the parks movement. There was tremendous excitement and energy for a global commitment to protected areas that is commensurate with the ecological and social challenges we face.

The days of protecting wild nature are not, and should not, be in the past. A bolder, resurgent conservation movement need not settle for an agenda based on trying to ameliorate the effects of humanity's numbers and overconsumption. Rather, it might sound a clarion call for a peace treaty between humans and nature, a cease-fire in industrial humanity's war on wild nature. The most tangible sign of that rapprochement would be the encircling ribbons of green and blue, strongholds of terrestrial and marine ${ }^{13}$ wildness, around the globe. It would be a profoundly pro-life movement, articulating the value of protecting nature for biodiversity, for humanity, for climate stability, for peace, and for future generations—of otters and people.

While he did not originate the aphorism, Martin Luther King Jr., the American civil rights leader, famously said, "The arc of the moral universe is long but it bends toward justice." That long arc bends fitfully in our 
diverse human tribe and, if we open our eyes to the natural world, we see that it also bends toward justice-and diversity, and beauty, and wildness-in the whole community of life.

The fundamental choice for our species is whether we will continue striving to be the planetary manager, the gardener-in-chief, or become a respectful member in the community of life. With every action to reassert the dominion of beauty, diversity, and wildness over the Earth-each hectare protected, each habitat secured-we tug the universe a bit more toward justice. That is the overarching story of conservation-past, present, and future. 